\title{
Outcomes after Cervical Duraplasty for Monomelic Amyotrophy (Hirayama Disease): Results of a Case-Control Study of 60 Patients
}

\author{
Sumit Thakar ${ }^{1}$ Aditya Atal Arun ${ }^{1}$ Niranjana Rajagopal ${ }^{1}$ Saritha Aryan ${ }^{1}$ Dilip Mohan ${ }^{1}$ \\ Joshy E. Vijayan ${ }^{2}$ Alangar S. Hegde ${ }^{1}$ \\ ${ }^{1}$ Department of Neurosurgery, Sri Sathya Sai Institute of Higher \\ Medical Sciences, Bengaluru, Karnataka, India \\ ${ }^{2}$ Department of Neurology, Sri Sathya Sai Institute of Higher Medical \\ Sciences, Bengaluru, Karnataka, India \\ Address for correspondence Sumit Thakar, MCh, Department of \\ Neurosurgery, Sri Sathya Sai Institute of Higher Medical Sciences, \\ Bengaluru 560066, Karnataka, India \\ (e-mail: sumit.thakar@gmail.com).
}

J Neurosci Rural Pract 2021;12:642-651.

\begin{abstract}
Background The optimal management and the role of surgery in monomelic amyotrophy, also known as Hirayama disease (HD), remain controversial. In the largest series of patients with HD managed by cervical duraplasty $(C D)$, this study compares the outcomes between conservative and surgical management.

Methods A retrospective case-control study was performed on 60 patients with HD. The cases consisted of 30 patients who underwent $C D$, and 30 age- and sex-matched controls who managed with long-term collar wear. Clinical improvement was recorded using two patient-reported outcome measures-the Odom's scale and a self-rated hand grip strength score. Median and ulnar compound muscle action potential (CMAP) amplitudes and various magnetic resonance imaging parameters were recorded.

Results None of the controls experienced clinical improvement at follow-up; 90\% remained status quo at $24.33 \pm 9.38$ months. Seventy-six percent of the operated patients demonstrated clinical improvement at $29.61 \pm 12.78$ months, and a majority of them reported moderately better grip strength. The preoperative anteroposterior diameter (APD) of the surgical group improved from $0.74 \pm 0.13$ to $0.86 \pm 0.21(p=0.01)$, and the cord demonstrated a significant decrease in forward migration on flexion $(0.20 \pm 0.11$ and $0.03 \pm 0.07$ preoperatively and at follow-up, respectively, $p<0.0001)$. Patients with clinical improvement demonstrated significantly better mean APD and median and ulnar CMAP values than those who did not improve $(p<0.0001)$. The mean cervical alignment did not change significantly at follow-up $(p=0.13)$.

\section{Keywords}

- monomelic amyotrophy

- Hirayama disease

- cervical duraplasty

Conclusions This study shows that CD can significantly alter the clinical course of patients with progressive symptoms of HD. This approach successfully arrests the forward migration of the cervical cord on flexion and promotes morphological recovery of the cord. A majority of the patients undergoing CD demonstrate clinical and electrophysiological improvement at mid-term follow-up.
\end{abstract}

published online September 22, 2021
DOI https://doi.org/ 10.1055/s-0041-1735248. ISSN 0976-3147.

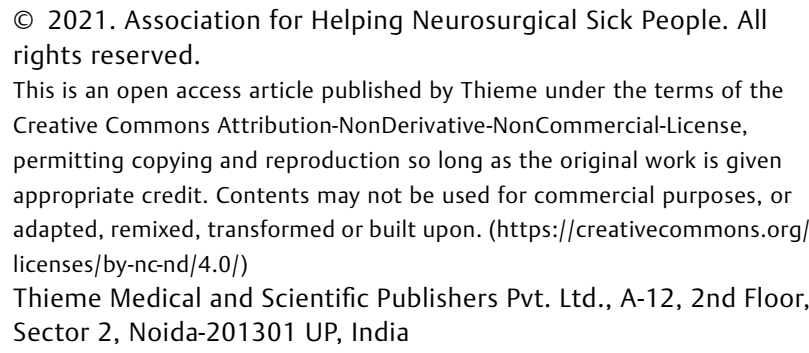

(c) 2021. Association for Helping Neurosurgical Sick People. All rights reserved.

This is an open access article published by Thieme under the terms of the Creative Commons Attribution-NonDerivative-NonCommercial-License, permitting copying and reproduction so long as the original work is given appropriate credit. Contents may not be used for commercial purposes, or adapted, remixed, transformed or built upon. (https://creativecommons.org/ licenses/by-nc-nd/4.0/)

Thieme Medical and Scientific Publishers Pvt. Ltd., A-12, 2nd Floor, Sector 2, Noida-201301 UP, India 


\section{Introduction}

Monomelic amyotrophy, also known as Hirayama disease (HD) or juvenile muscular atrophy of the distal upper extremities, is an unusual, self-limiting disease that primarily affects males in the second and third decades. It is characterized by selective unilateral or bilateral asymmetric amyotrophy of the hand and forearm muscles supplied by the C7T1 myotomes, without objective sensory disturbance or lower limb involvement. ${ }^{1,2}$ The clinical manifestations of the disease are hypothesized to be related to excessive forward displacement of the posterior dura and cord during flexion. ${ }^{3}$ In the absence of evidence-based guidelines, the optimal management of HD and the selection of the surgical approach have been largely based on the physician's personal preference. While most of the operative series on patients requiring surgery have reported outcomes after anterior fusion procedures, ${ }^{4-8}$ there is a glaring lack of data on outcomes after posterior decompression in HD. Considering this gap of knowledge, the objective of this study was to analyze the efficacy of cervical duraplasty (CD) in the largest documented series of HD patients managed by a posterior approach.

\section{Materials and Methods}

\section{Patient Population}

This was a retrospective matched case-control study of 60 patients with HD managed at a single-institute over an 8year-period from January 2012 to January 2020. All patients included in the study were diagnosed to have HD by the neurologists based on the criteria proposed by Hirayama et al. ${ }^{1,2}$ The criteria included weakness and wasting predominantly in the $\mathrm{C} 7, \mathrm{C} 8$, and $\mathrm{T} 1$ myotomes in one upper limb or asymmetrically in both upper limbs, insidious onset of symptoms in adolescents or adults in their early twenties, initial fast progression for 1 to 3 years, irregular coarse tremors in the fingers of the affected hand or hands, mild transient worsening of symptoms on exposure to the cold, electromyographic evidence of chronic denervation in the clinically or sub-clinically affected muscles, and an absence of objective sensory loss.

Since the currently accepted first line of management of HD is cervical immobilization with a collar, all the 60 patients were initially advised to wear a hard collar for 6 weeks. This was done to assess their compliance with this treatment modality. Patients not comfortable with the idea of long-term collar wear or those who were not compliant with collar-wear in the 6 -week trial period were then referred for surgery.

The cases consisted of 30 patients who underwent $C D$, while the controls consisted of 30 age- and sex-matched patients with HD who were managed conservatively with long-term collar wear. The exclusion criteria for the study included history of cervical spine trauma or hand surgery, or the presence of any other concomitant spinal disease. Informed consent was obtained from all the patients prior to surgery. The study was approved by the institutional review board and has been reported as per the STROBE (STrengthening the Reporting of OBservational studies in Epidemiology) guidelines.

\section{Surgical Procedure}

A standardized procedure was followed for all the surgically managed patients. Following fiberoptic intubation, patients were positioned prone with the head secured in pins and neck in neutral position. Laminectomy was performed at the levels corresponding to the maximum dilatation of the cervical epidural venous plexus seen on flexion magnetic resonance imaging (MRI). Following laminectomy, the underlying epidural venous plexus was systematically sought for, coagulated, and resected. A midline dural opening was then made corresponding to the laminectomy levels, and an expansile duraplasty performed using fascia lata. Posterior fixation was not performed in any of the cases. The patients were ambulated the day after surgery with a cervical collar that they wore for 1 to 2 weeks.

\section{Outcome Assessment}

Patients in both groups were assessed clinically at a minimum follow-up of 6 months after conservative or surgical treatment. For patients in the surgical group, various radiological and electrophysiological characteristics were also assessed at the follow-up visits, and compared with the preoperative status.

Clinical outcome in all patients was assessed using two patient-reported outcome measures (PROMs)- the Odom's scale ${ }^{9}$ and a self-rated hand grip strength (SRHGS) score. PROMs are being increasingly used in outcome studies, and validated PROMs such as the Odom's scale ${ }^{10}$ are no longer considered a subjective measure, but a robust, objective assessment of the patient's functional status. ${ }^{11}$ While the Odom's scale has been previously used to assess outcome after surgery for HD, hand grip strength assessment has not been performed in previous studies on HD. We used five subjective categories for the SRHGS score to quantify the degree of patient-perceived change in their hand grip strength at follow-up:

$0=$ worsened, $1=$ same, $2=$ slightly better, $3=$ moderately better, $4=$ extremely better. Questions on self-rated grip strength have been previously found to correlate well with actual grip-strength values obtained on a dynamometer. ${ }^{12}$

Patients were categorized into two predefined subgroups based on their Odom's scale ratings at the last follow-up point. The "improvement" subgroup included patients with "excellent" and "good" results on the Odom's scale, while patients with "fair" or "poor" scores constituted the "no improvement" subgroup. Clinical "deterioration" was defined as a "poor" Odom's score and/ or a SRHGS score of 0.

\section{Electrophysiological Assessment}

Electromyography (EMG) and nerve conduction studies were performed in all patients to establish the diagnosis of HD. Thenar and hypothenar compound muscle action potentials (CMAPs) were recorded at the abductor pollicis brevis and abductor digiti minimi in response to stimulation of the median and ulnar nerves, respectively. The mean of the CMAPs at the wrist and elbow was calculated to arrive at 
the overall CMAP for each nerve. The mean overall ulnar/median (U/M) CMAP ratio was then calculated. For the analysis, values from the affected side were used in case of unilateral disease. For patients with bilateral disease, the amplitudes of the more affected hand were taken.

\section{Radiological Evaluation}

All patients underwent dynamic radiographs and gadolinium-enhanced cervical MRI in neutral and 45 degrees flexion. A uniform imaging protocol was used for all patients. The MRI measurement slab was manually positioned from the base of the occiput through the upper portion of the $\mathrm{C7}$ vertebral body. The axial MR slices were aligned parallel to the $\mathrm{C} 2-\mathrm{C} 3$ discs space.

The following key radiological characteristics associated with a diagnosis of HD were looked for at presentation: lower cervical cord atrophy on neutral MRI, loss of attachment between the posterior dural sac and laminae, forward mi- gration of the cord, and prominent enhancing epidural masslike venous plexus on flexion MRI ( - Fig. 1). Localized cord atrophy was defined as a relative decrease in cord size when compared with the normal cord above and below the affected levels on sagittal and axial T2-weighted sequences, and was recorded as unilateral, bilateral or absent. The following additional radiological parameters were assessed by two independent observers (AAA and NR) preoperatively and at follow-up in patients who underwent surgery. Cord morphology was objectively assessed by measuring the sagittal anteroposterior diameter (APD) of the lower cervical cord (defined as the cervical cord from C4-C7 levels) at the middisc line formed by a straight line connecting the midpoint of the anterior and posterior edges of the disc spaces from C4C5 to C7-T1 levels. The distance between the anterior and posterior edge of the spinal cord on the extension of this line was taken as the APD (-Fig. 2A). To reduce individual differences, the mean lower cervical APD was taken relative
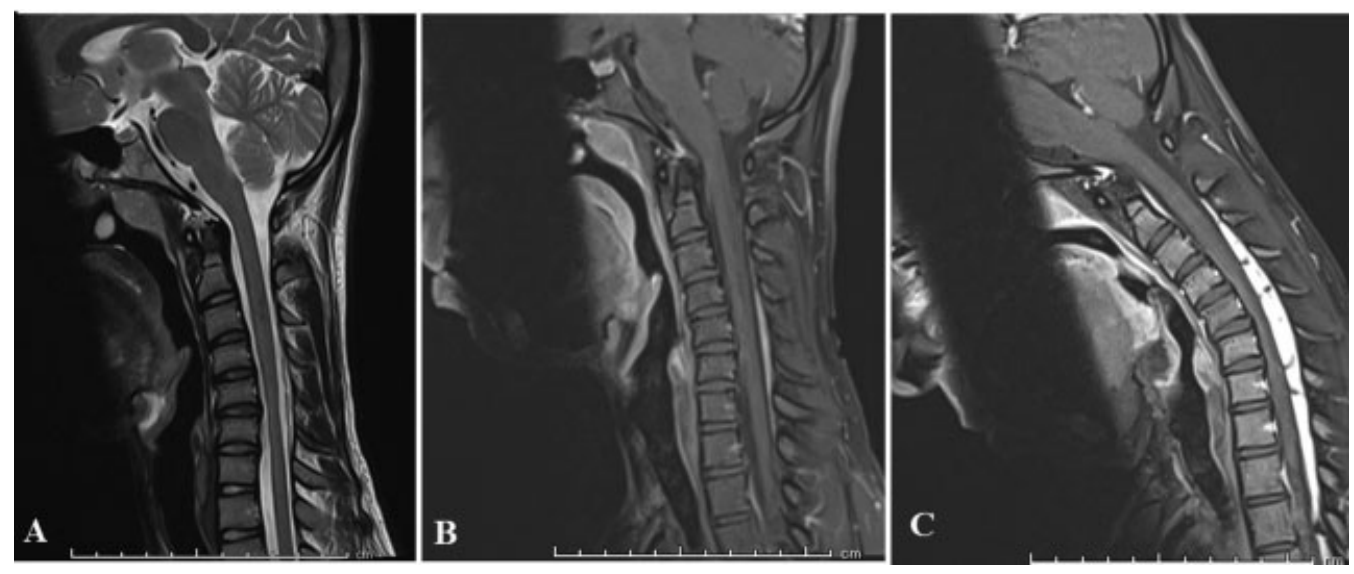

Fig. 1 Sagittal magnetic resonance imaging demonstrating the key radiological characteristics of Hirayama disease: (A) Neutral T2 sagittal image demonstrating lower cervical cord atrophy; gadolinium-enhanced T1-weighted sequences in (B) neutral and (C) flexion demonstrating forward migration of the cord and prominent enhancing epidural mass-like venous plexus on flexion.

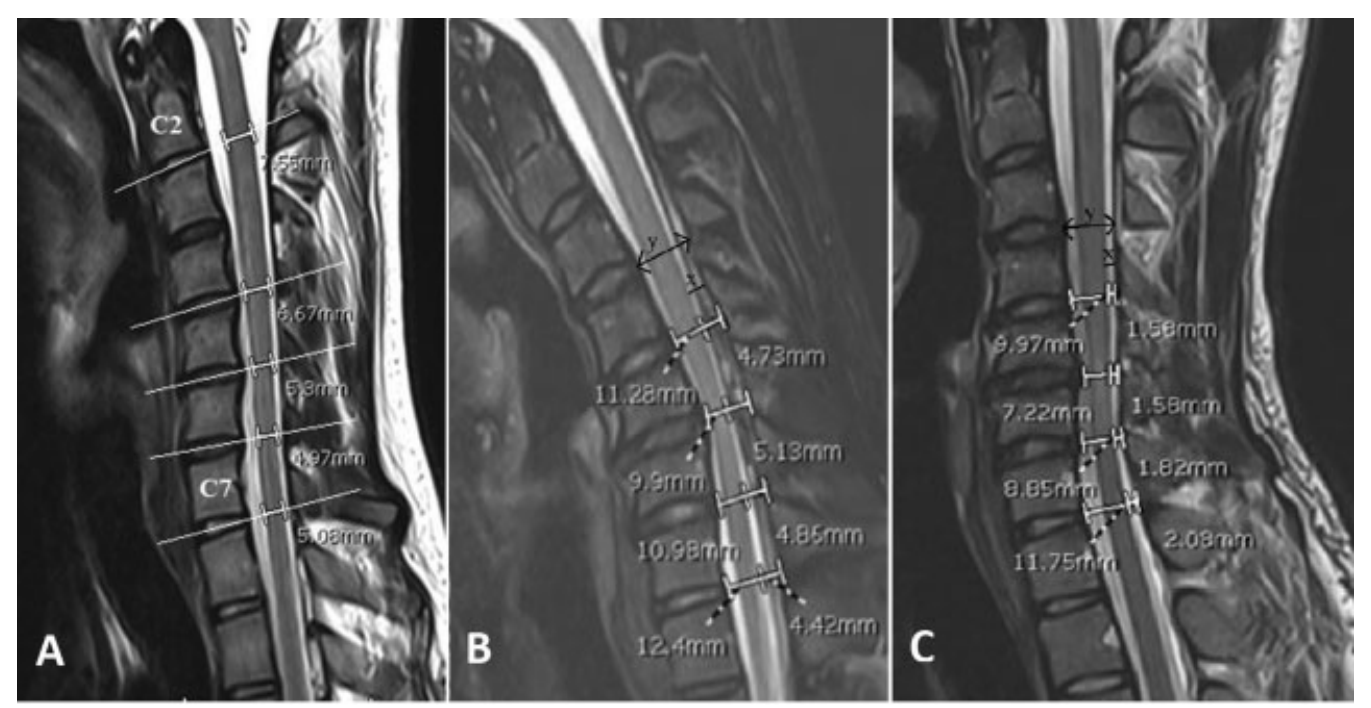

Fig. 2 T2 sagittal magnetic resonance section demonstrating (A) measurement of the anteroposterior diameter (APD) of the lower cervical cord at the mid-disc levels from C4 to C7 levels. C2-C3 APD was taken as reference value for each patient; (B) flexion and (C) neutral magnetic resonance imaging showing forward migration of the lower cervical cord from C4-C5 to C7-T1 levels. " $\mathrm{x}$ " is the distance between the posterior edge of the spinal cord and posterior edge of the spinal canal and " $y$ " is the distance between the anterior and posterior edges of the spinal canal. The forward migration of the cord on flexion was calculated as the difference between the $x / y$ ratios in (B) and (C). 
to the APD at C2-C3 a level that was free of compression in all patients and hence used as an internal reference.

Forward migration of the lower cervical cord was measured on sagittal images at the mid-disc lines from C4-C5 to C7-T1 levels. The distance between the posterior edge of the spinal cord and posterior edge of the spinal canal was termed "x," and the distance between the anterior and posterior edges of the spinal canal was termed "y" (-Fig. 2B, C). The " $\mathrm{x} / \mathrm{y}$ " ratio was thus the relative position of the posterior edge of the cord in the canal. The difference in this ratio in flexion and neutral positions was used as the indicator for the relative forward migration of the spinal cord in flexion. The mean forward migration of the lower cervical cord at various levels was used for analysis. Cervical alignment was measured on neutral radiographs by recording the $\mathrm{C2}-\mathrm{C} 7$ Cobb's angle, that is, the angle between the lines parallel to the inferior endplates of C2 and C7 vertebral bodies. Instability was assessed on dynamic radiographs before surgery and at follow-up.

\section{Statistical Analysis}

The statistical software SPSS 17.0 (SPSS, Chicago, Illinois, United States) was used for analysis. Using a sample size of 30 , an $\alpha$ value of 0.05 , and an effect size of 0.8 used from a previous surgical series, ${ }^{13}$ the power of our study was calculated to be 0.9 . Dichotomous data are described as

Table 1 Clinical and radiological characteristics of the study cohort $(n=60)$

\begin{tabular}{|l|l|}
\hline Clinical features & $\begin{array}{l}\text { Number of } \\
\text { patients (\%) }\end{array}$ \\
\hline Hand/forearm muscle weakness & $60(100)$ \\
\hline Hand/forearm muscle wasting & $60(100)$ \\
\hline Tremors on finger extension & $36(60)$ \\
\hline Fasciculations & $18(30)$ \\
\hline Sensory symptoms & 0 \\
\hline Pyramidal tract involvement & 0 \\
\hline Bladder symptoms & 0 \\
\hline Radiological characteristics & \\
\hline Lower cervical cord atrophy on axial MRI & \\
\hline None & $8(13.33)$ \\
\hline Unilateral & $33(55)$ \\
\hline Bilateral & $19(31.67)$ \\
\hline Loss of attachment between the \\
posterior dural sac and laminae & $60(100)$ \\
\hline Enhancing venous plexus on flexion MRI & $60(100)$ \\
\hline Number of cervical levels & \\
\hline 3 & $11(18.33)$ \\
\hline 4 & $12(20)$ \\
\hline 5 & $32(53.33)$ \\
\hline 6 & $5.33)$ \\
\hline
\end{tabular}

Abbreviation: MRI, magnetic resonance imaging. counts and percentages, whereas continuous data are presented as means \pm standard deviation. The unpaired $t$-test was used to compare preoperative and follow-up data for the whole cohort, and for the comparison of outcomes between the subgroups based on clinical improvement. A " $p$ " value of less than 0.05 was considered significant.

\section{Results}

\section{Demographics and Clinicoradiological Characteristics}

All the study subjects were males with a mean age of $20.39 \pm 2.93$ years with the duration of symptoms ranging from 14 to 48 months. The clinical and radiological characteristics of the cohort are listed in - Table 1. A majority of the patients presented with bilateral, asymmetric symptoms, or signs. The levels of enhancement in the cervical cord varied from three to six, with $\mathrm{C} 5-\mathrm{C} 7$ being the commonest levels of involvement. Cord atrophy on axial MRI was noted in 52 patients, and was unilateral (-Fig. 3A) in 33 (55\%) patients and bilateral in 19 (32\%) patients. The clinical and electrophysiological characteristics of the cases and controls were similar (-Table 2).

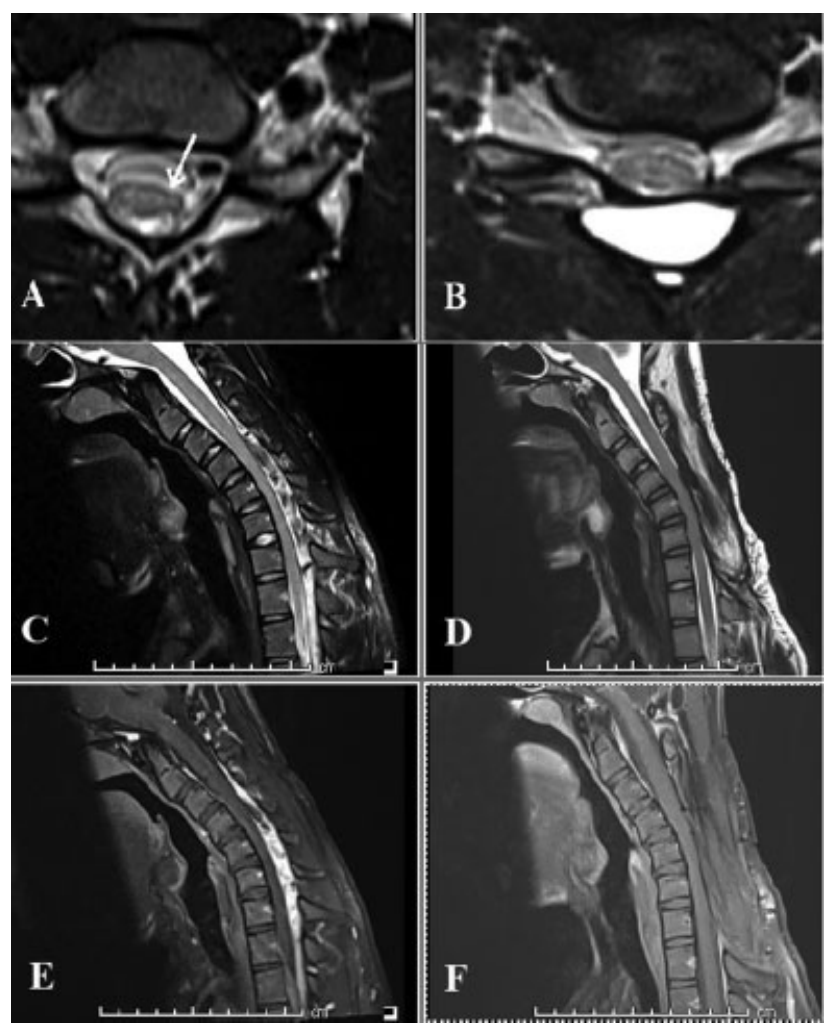

Fig. 3 Comparison of preoperative and follow-up magnetic resonance imaging of a 22-year-old man who presented with unilateral symptoms of Hirayama disease and underwent C3-C7 laminectomy. T2 axial images demonstrating (A) unilateral cord atrophy (arrow) at presentation and (B) cord expansion at follow-up 9 months after surgery; T2 sagittal images on flexion demonstrating (C) multiple flow voids from $\mathrm{C} 3$ to $\mathrm{C} 7$ and lower cervical cord compression at presentation, and (D) disappearance of the flow voids and absence of cord compression at follow-up; gadolinium-enhanced T1 sagittal images in flexion demonstrating $(\mathrm{E})$ intense contrast enhancement in the dilated epidural venous plexus before surgery and $(F)$ no residual enhancement at follow-up. 
Table 2 Clinical and electrophysiological characteristics of the cases and controls

\begin{tabular}{|l|l|l|l|}
\hline & $\begin{array}{l}\text { Cases } \\
(\boldsymbol{n}=30)\end{array}$ & $\begin{array}{l}\text { Controls } \\
(\boldsymbol{n}=30)\end{array}$ & $p$-Value \\
\hline Mean duration of symptoms (mo) & $23.56 \pm 13.49$ & $25.23 \pm 14.16$ & 0.64 \\
\hline Mean U/M CMAP ratio & $0.95 \pm 0.89$ & $0.94 \pm 0.13$ & 0.95 \\
\hline & Number of patients (\%) & \\
\hline Weakness/wasting & \multicolumn{2}{|l|}{} & \\
\hline Unilateral & $11(37)$ & $14(47)$ & 0.42 \\
\hline Bilateral asymmetric & $19(63)$ & $16(53)$ & 0.42 \\
\hline Muscle groups involved & & & \\
\hline Hand & $11(37)$ & $12(40)$ & 0.78 \\
\hline Hand and forearm & $19(63)$ & $18(60)$ & 0.78 \\
\hline
\end{tabular}

Abbreviation: U/M CMAP, ulnar and median compound muscle action potential.

\section{Electrophysiological Findings}

All patients had EMG evidence of chronic denervation in the C7-T1 myotomes. nerve conduction velocity studies for the entire cohort demonstrated less than normal mean CMAP values for the median and ulnar nerves $(3.87 \pm 0.50 \mathrm{mV}$ and $3.51 \pm 0.53 \mathrm{mV}$ respectively). The mean $\mathrm{U} / \mathrm{M}$ CMAP ratio was $0.88 \pm 0.11$. The results of the sensory nerve conduction tests were normal in all patients.

\section{Clinical Outcomes in the Surgical Group}

Follow-up clinical data was available in 25 (83\%) patients in the surgical group. All patients in the surgical group underwent $C D$ as outlined earlier. $C D$ was performed at three levels in a majority (24/30) of the patients, and at more than three levels in the remaining few. A majority of the patients who underwent $C D$ demonstrated clinical improvement at a mean follow-up of $29.61 \pm 12.78$ months (-Table 3 ), with 15 patients reporting "excellent" outcomes on the Odom's scale. A majority of the patients reported a SRHGS score of 3 (moderately better hand grip) (-Table 3 ). There was no difference in clinical improvement between patients with unilateral and bilateral, asymmetric disease $(p=0.34)$. MRIs of the three patients with clinical "deterioration" showed progressive atrophy of the lower cervical cord, and these patients were advised close follow-up.

\section{Clinical Outcomes in the Control Group}

Follow-up clinical data was available in 20 (66\%) patients in the control group being managed with long-term collar wear. None of these patients reported clinical improvement on the Odom's scale; 18 (90\%) remained status quo and 2 reported "poor" scores at a mean follow-up of $24.33 \pm 9.38$ months (-Table 3). A majority of the patients reported a SRHGS score of 1 (no improvement in hand grip). Two patients with clinical "deterioration" refused surgical intervention and opted to continue conservative treatment.

\section{Postduraplasty Radiological Changes}

The cervical cord morphology at different levels relative to the C2-C3 APD is listed in - Table 4. The mean lower cervical APD improved from a preoperative value of $0.74 \pm 0.13$ to
Table 3 Follow-up Odom's scale and SRHGS scores compared between cases and controls

\begin{tabular}{|c|c|c|c|}
\hline & $\begin{array}{l}\text { Cases } \\
(n=25)\end{array}$ & $\begin{array}{l}\text { Controls } \\
(n=20)\end{array}$ & $p$-Value \\
\hline \multicolumn{4}{|l|}{$\begin{array}{l}\text { Subgroups based } \\
\text { on Odom's score }\end{array}$} \\
\hline Clinical improvement & $19(76 \%)$ & 0 & $<0.001$ \\
\hline - Excellent & $15(60 \%)$ & 0 & \\
\hline • Good & 4 (16\%) & 0 & \\
\hline No improvement & $6(24 \%)$ & $20(100 \%)$ & $<0.001$ \\
\hline - Fair & $3(12 \%)$ & 18 (90\%) & \\
\hline \multicolumn{4}{|l|}{ SRHGS score } \\
\hline 0 & 3 & 2 & \\
\hline 1 & 3 & 18 & \\
\hline 2 & 4 & 0 & \\
\hline 3 & 11 & 0 & \\
\hline 4 & 4 & 0 & \\
\hline $\begin{array}{l}\text { Mean follow-up } \\
\text { period (in months) } \\
\pm S D\end{array}$ & $\begin{array}{l}29.61 \pm \\
12.78\end{array}$ & $\begin{array}{l}24.33 \pm \\
9.38\end{array}$ & 0.13 \\
\hline
\end{tabular}

Abbreviations: SD, standard deviation; SRHGS, self-rated hand grip strength.

$0.86 \pm 0.21(p=0.01)$ at follow-up. - Table 4 also lists the difference in " $\mathrm{x} / \mathrm{y}$ " ratios in flexion and neutral position, denoting the forward migration of the cord, at different levels. Maximum cord migration occurred at C6-C7 level. Follow-up MRIs demonstrated a significant arrest of this flexion-induced cord migration $(0.20 \pm 0.11$ and $0.03 \pm 0.07$ preoperatively and at follow-up respectively, $p<0.0001$ ). This finding was accompanied by the disappearance of the enhancing venous plexus on flexion in all patients at follow-up (-Fig. 3). 
Table 4 Radiological characteristics of the surgical group

\begin{tabular}{|l|l|l|l|}
\hline & Preoperative & Follow-up & $p$-Value \\
\hline $\begin{array}{l}\text { Mean anterior- } \\
\text { posterior cord } \\
\text { diameter }\end{array}$ & & & \\
\hline C4-C5 & $0.86 \pm 0.12$ & $0.96 \pm 0.12$ & \\
\hline C5-C6 & $0.71 \pm 0.12$ & $0.80 \pm 0.19$ & \\
\hline C6-C7 & $0.72 \pm 0.11$ & $0.83 \pm 0.11$ & \\
\hline C7-T1 & $0.77 \pm 0.09$ & $0.84 \pm 0.09$ & \\
\hline Mean & $0.74 \pm 0.13$ & $0.86 \pm 0.21$ & 0.01 \\
\hline $\begin{array}{l}\text { Mean forward } \\
\text { cord migration } \\
\text { (x/y in flexion-x/y } \\
\text { in neutral) }\end{array}$ & & & \\
\hline C4-C5 & $0.15 \pm 0.13$ & $0.05 \pm 0.20$ & \\
\hline C5-C6 & $0.21 \pm 0.14$ & $0.01 \pm 0.11$ & \\
\hline C6-C7 & $0.24 \pm 0.13$ & $0.01 \pm 0.10$ & \\
\hline C7-T1 & $0.20 \pm 0.10$ & $0.06 \pm 0.08$ & \\
\hline Mean & $0.20 \pm 0.11$ & $0.03 \pm 0.07$ & $<0.0001$ \\
\hline $\begin{array}{l}\text { C2-C7 Cobb's } \\
\text { angle }\end{array}$ & $4.24 \pm 3.88$ & $2.19 \pm 5.95$ & 0.13 \\
\hline
\end{tabular}

Subgroup analysis (based on clinical "improvement" and "no improvement" subgroups) (-Fig. 4) in the surgical group revealed a similar decrease in forward cord migration in the two subgroups at follow-up. Patients in the "improvement" subgroup, however, demonstrated significantly better mean cervical APDs.

\section{Alignment before Surgery and at Follow-Up}

The mean preoperative C2-C7 Cobb's angle of $4.24 \pm 3.88$ degrees did not change significantly at a mid-term follow-up period of close to 30 months after surgery $(2.19 \pm 5.95$ degrees, $p=0.13$ ). There were no differences in alignment between the subgroups with and without clinical improvement $(p=0.42)$. None of the patients had evidence of instability on dynamic radiographs at presentation or at follow-up. There was no instance of symptomatic kyphosis at follow-up.

\section{Postoperative Electrophysiological Changes}

Postintervention analysis of the entire surgical group revealed no significant change in the median or ulnar nerve CMAPs ( $3.95 \pm 0.58 \mathrm{mV}$ and $3.73 \pm 0.57 \mathrm{mV}$ respectively), or in the mean $\mathrm{U} / \mathrm{M}$ ratio $(0.94 \pm 0.20)$. Subgroup analysis (-Fig. 4), however, yielded different results, with patients in the "improvement" subgroup demonstrating significantly better U/M CMAP ratios at follow-up than patients in the "no improvement" subgroup.

\section{Complications}

There were no perioperative surgical complications such as cerebrospinal fluid leakage or development of new neurological deficits. One patient had a superficial wound infection that was managed conservatively.

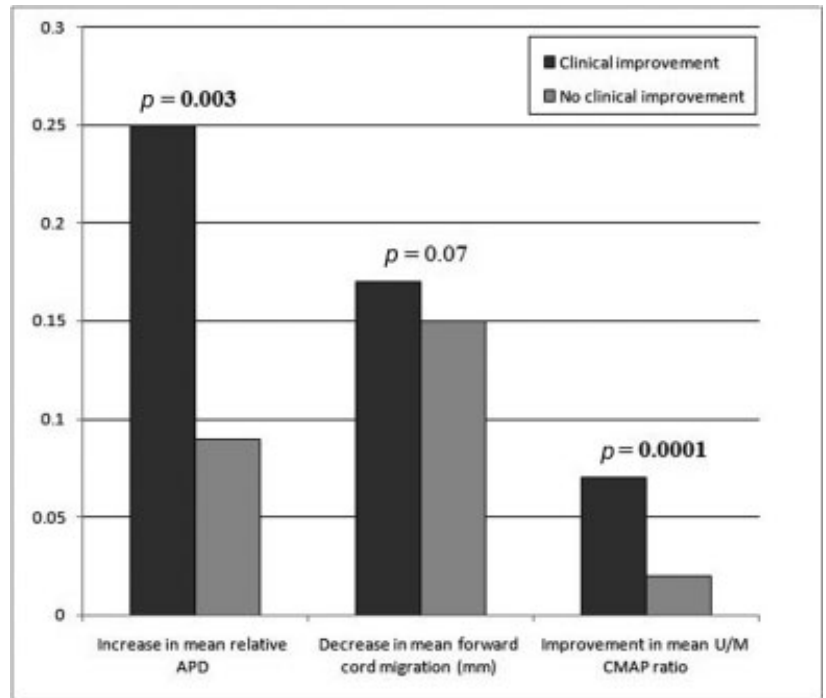

Fig. 4 Bar-chart comparing postsurgical radiological and electrophysiological changes between subgroups with and without clinical improvement. APD, anteroposterior diameter; U/M CMAP, ulnar and median compound muscle action potential.

\section{Discussion}

\section{Pathogenesis of HD-Theories and Substrates}

The flexion myelopathy of HD is believed to be related to repeated flexion-induced microtrauma in the anterior horn cells and ventral roots of the lower cervical cord. The ensuing ischemia in these neural elements manifests as the characteristic distal amyotrophy. ${ }^{14}$ While some of these pathological findings have been confirmed at autopsy and neuropathologic studies, ${ }^{2,15}$ the underlying mechanism of the flexion-induced cord damage remains a subject of debate. ${ }^{16,17}$

The most widely accepted theories for the pathogenesis of HD are dural-based. The first is that of an abnormally tight dura causing anterior displacement and compression of the cord on being stretched in flexion. ${ }^{17}$ This has been corroborated by the loss of elastin fibers and normal dural architecture in surgically resected specimens. ${ }^{18,19}$ Another theory suggests an overstretch of the dura on flexion occurring due to disparity between the growth of the vertebral column and the spinal content. ${ }^{20}$ Since males tend to have faster rates of vertebral column growth than females, this disproportionate-growth theory can also explain the male preponderance seen in HD. ${ }^{20}$

Non dural-based theories of HD include compression by anteriorly located osteophytic bars, ${ }^{17}$ flexion-induced venous stagnation, ${ }^{16,21,22}$ and underlying instability. ${ }^{6,23}$ The genesis of the latter hypothesis is related to the effectiveness of collar wear and reports of abnormal alignment ${ }^{24}$ and range of neck flexion ${ }^{25}$ rather than any definite radiological evidence of instability.

\section{Conservative versus Surgical Management: Key Findings of Our Study}

Conservative therapy of HD involves protracted collar-wear with or without the usage of neurotrophic drugs. ${ }^{26}$ Collar immobilization reportedly prevents the dynamic damage to the cervical motor neurons. ${ }^{6}$ This in turn stabilizes the 
clinical course of the disease, especially in patients with a shorter duration of illness. ${ }^{26,27}$ While collar-wear is considered the first line of management of HD, a recently established clinician-led consensus statement recommended surgical intervention in cases of relapse or a protracted course of the disease, or if the patient is uncomfortable with the idea of long-term collar wear. ${ }^{26}$

Our study, one of the few large case-control studies on the disease, demonstrated stabilization of the clinical status in almost all patients managed with long-term collar-wear. None of these patients, however, reported any clinical improvement, and two of them had worsened at follow-up. On the other hand, a majority of our patients managed with $C D$ reported improvement of their symptoms at a similar followup period, indicating that the surgical procedure altered the clinical course of our patients to a greater degree than collarwear did. It may be argued that varying disease severity at presentation could have contributed to this finding. This was, however, unlikely, given that both the groups were similar with respect to their duration of symptoms, clinicoradiological, and electrophysiological characteristics.

\section{Changes in Cord Morphology after Duraplasty}

Follow-up imaging of the surgical group demonstrated expansion of the lower cervical cord in almost all the patients. Similar morphological changes in the spinal cord are known to occur after decompression in conditions like cervical spondylotic myelopathy (CSM) $)^{28,29}$ and have been postulated to be reflective of improvement in axonal transport. ${ }^{29}$ Three patients in the surgical group reported progression of symptoms even after surgery. Repeat imaging in these patients ruled out instability or kyphosis and demonstrated progressive worsening of cord morphology. The cause of the clinical deterioration and cord changes remained unexplained.

\section{Other Postsurgical Radiological Changes}

The pathognomonic forward migration of the dura and cord associated with an intensely-enhancing epidural mass on flexion MRI in HD has been attributed to an expansion of the venous plexus between an overstretched dural sac and the posterior wall of the spinal canal. ${ }^{30-32}$ All our patients demonstrated complete radiological resolution of the phenomenon at follow-up.

There have been reports of abnormal cervical alignment and sagittal balance in patients with HD. ${ }^{24,25,33}$ These have not been documented to correlate with disease severity or clinical outcomes. In our study, CD following a laminectomy did not affect the overall cervical alignment at mid-term follow-up.

\section{Electrophysiological Parameters and Postoperative Changes}

The CMAPs of the ulnar and median nerves and the $\mathrm{U} / \mathrm{M}$ CMAP ratio are decreased in HD. ${ }^{34}$ The latter has been found to be a more sensitive and specific index of the disease than the individual CMAP values. ${ }^{35}$ In our study also, both the individual CMAP values and the mean U/M CMAP ratio were reduced at presentation. The subgroup of patients with clinical improvement had significantly better ratios than those in the non-improvement subgroup.

\section{Surgical Options in HD}

Even though there is level III evidence to back the effectiveness of surgical intervention in $\mathrm{HD},{ }^{6,8,21,36}$ there is no clarity on the optimal surgical approach. ${ }^{26}$ The available surgical options include a variety of decompressive and fusion procedures, all of which attempt to address the pathology of a tight dural canal and subsequent flexion-induced cord compression. Fusion procedures, anterior or posterior, arrest segmental movement, and prevent the dural migration and cord compression during flexion. Duraplasty after laminectomy or laminoplasty, ${ }^{21,36-40}$ on the other hand, directly addresses the pathology of the tight dural canal. An added advantage of a posterior procedure is that it also addresses the flexion-induced dilatation of the epidural venous plexus seen in HD. This phenomenon is postulated to aggravate cord ischemia in the lower cervical region by its deleterious effects on the spinal cord microcirculation during flexion or Valsalva maneuvers. ${ }^{16,21}$

\section{Selection of Surgical Procedure}

A literature search revealed that while over 300 cases of $\mathrm{HD}^{6,8,26}$ were managed with anterior or posterior fusion, only 16 patients were treated with duraplasty without fusion (-Table 5). ${ }^{16,21,36-40}$ Ours is the first large series that critically evaluates CD as a surgical option in HD.

Since all our patients had lordotic spines and none of them had any radiological evidence of instability, we chose not to subject any of them to a fusion procedure. Fusion sparing surgery would theoretically also allow for maintenance of cervical mobility-an important factor to consider in the management of the young population typically affected by HD. On the downside, there is an inherent risk of postoperative kyphosis developing after multilevel cervical laminectomy. This phenomenon has, however, not been demonstrated to affect functional outcomes at long-term follow-up. ${ }^{41-43}$

We chose to perform duraplasty via laminectomy in our patients. While laminoplasty could have been considered in the young study subjects undergoing multilevel cervical decompression, there is no evidence to indicate the superiority of laminoplasty over laminectomy in HD. The comparison between the two procedures in literature is mainly drawn from studies on $\mathrm{CSM}^{44}$ a disease that is entirely different from HD in terms of pathogenesis, natural history, and the age profile of affected individuals. Further, literature also suggests that laminoplasty is not superior to laminectomy in patients without preexisting instability, ${ }^{44,45}$ with no observable differences with regard to functional outcomes.

\section{Implications of Our Study}

HD is labeled a self-limiting disease, with long-term collarwear being one of the widely adopted modalities to arrest disease progression. With more than three-quarters of our operated patients experiencing clinical improvement, our study demonstrates that surgical intervention via $C D$ not only arrests disease progression of the disease, but can even improve symptoms. CD uniformly halts forward dural migration and promotes cord expansion at follow-up (-Fig. 3 ). 
Table 5 Review of published cases of HD treated with laminectomy/laminoplasty and duraplasty without fusion

\begin{tabular}{|c|c|c|c|c|c|c|}
\hline Author & Year & $\begin{array}{l}\text { Number } \\
\text { of patients }\end{array}$ & $\begin{array}{l}\text { Age (in years) } \\
\text { / Sex }\end{array}$ & Affected side & $\begin{array}{l}\text { Follow-up } \\
\text { duration } \\
\text { (months) }\end{array}$ & Clinical status \\
\hline Fujimoto $^{38}$ & 2002 & 3 & $\begin{array}{l}18 / \mathrm{M}, 17 / \mathrm{M} \\
17 / \mathrm{M}\end{array}$ & $\begin{array}{l}\text { Unilateral in all } \\
3 \text { patients }\end{array}$ & $36,38,48$ & $\begin{array}{l}\text { Improvement in ADL disability } \\
\text { score in all } 3 \text { patients }\end{array}$ \\
\hline Arrese $^{37}$ & 2009 & 1 & 19/M & Unilateral & 24 & Stabilization of symptoms \\
\hline $\operatorname{Lin}^{39}$ & 2010 & 1 & $25 / M$ & Unilateral & 39 & $\begin{array}{l}\text { Improvement in atrophy; no } \\
\text { change in strength }\end{array}$ \\
\hline Ciceri $^{16}$ & 2010 & 1 & $15 / M$ & Bilateral & 12 & Stabilization of symptoms \\
\hline Ito $^{36}$ & 2014 & 6 & $\begin{array}{l}20 / \mathrm{M}, 19 / \mathrm{M} \\
17 / \mathrm{M} \\
15 / \mathrm{M}, 18 / \mathrm{M} \\
23 / \mathrm{M}\end{array}$ & $\begin{array}{l}\text { Unilateral in } \\
3 \text { patients, } \\
\text { bilateral in } \\
3 \text { patients }\end{array}$ & $\begin{array}{l}75,70,69 \\
27,24,12\end{array}$ & $\begin{array}{l}\text { Improvement in bilateral grip } \\
\text { strength in } 5 \text { patients; } \\
\text { stabilization of atrophy }\end{array}$ \\
\hline Vitale 40 & 2016 & 1 & - & - & - & - \\
\hline Brandicourt $^{21}$ & 2018 & 3 & $\begin{array}{l}16 / M, 17 / M \\
20 / M\end{array}$ & $\begin{array}{l}\text { Unilateral in } \\
1 \text { patient, } \\
\text { bilateral in } \\
2 \text { patients }\end{array}$ & $36,36,24$ & $\begin{array}{l}\text { Stabilization of symptoms and } \\
\text { improvement in strength }\end{array}$ \\
\hline Present series & 2020 & $\begin{array}{l}30 \text { cases } \\
30 \text { controls }\end{array}$ & $\begin{array}{l}20.39 \pm 2.93 \\
\text { (mean); } \\
\text { all males }\end{array}$ & $\begin{array}{l}\text { Unilateral in } \\
25 \text { patients, } \\
\text { bilateral in } \\
35 \text { patients }\end{array}$ & $\begin{array}{l}29.61 \pm 12.78 \\
24.33 \pm 9.38\end{array}$ & $\begin{array}{l}\text { Cases: Improvement in } 19 / 25 \\
\text { ( } 76 \%) \text { patients; no improvement/ } \\
\text { worsening in } 6(24 \%) \text { patients. } \\
\text { Controls: No improvement in } \\
18 / 20(90 \%) \text { patients; worsening in } \\
2(10 \%) \text { patients }\end{array}$ \\
\hline
\end{tabular}

Abbreviations: ADL, activities of daily living; HD, Hirayama disease; $M$, male.

Importantly, the above gains are achieved without subjecting young patients to a fusion procedure with its mobility-related disadvantages; no significant alignment changes associated with the procedure were noted at mid-term follow-up. However, it may be cautioned that our average follow-up period of around 30 months may not have been sufficient to reveal substantial alignment changes. Larger scale prospective studies with longer follow-up will help to establish the utility of CD without fusion in HD.

\section{Study Limitations}

Our study has the inherent limitations of a retrospective analysis. Although the Odom's scale is a useful outcome tool, development and usage of a disease-specific scale for HD would provide a more robust outcome analysis. While our sample size was adequate, follow-up data could not be obtained in all the patients. A longer duration of follow-up would have provided more insight into the continuum of changes in cord morphology in HD, and may uncover potential post-laminectomy kyphotic changes requiring intervention.

\section{Conclusions}

This study shows that CD can significantly alter the clinical course of patients with progressive symptoms of HD. This approach successfully arrests the forward migration of the cervical cord on flexion and promotes morphological recovery of the cord. A majority of the patients undergoing CD demonstrate clinical improvement at mid-term follow-up. This subset of patients also demonstrates improvement in electrophysiological parameters.

Note

This article has been prepared using guidelines laid down by the institute. The institutional review board and ethics committee have granted approval for the study. The authors confirm that they have read the journal's position on issues involved in ethical publication and affirm that this report is consistent with those guidelines in accordance with the World Medical Association Declaration of Helsinki.

\section{Authors' Contributions}

S.T. was involved in conception, statistical analyses, preparation, and review of manuscript. A.A. was involved in data collection and review of final manuscript. N.R. was involved in data collection and review of final manuscript. S.A. was involved in critical feedback and review of final manuscript. D.M. was involved in study supervision and review of final manuscript. J.E.V. was involved in review of final manuscript. A.S.H. provided administrative support and review of the final manuscript. 
Funding

None.

\section{Conflict of interest \\ None declared.}

\section{References}

1 Hirayama K. [Juvenile muscular atrophy of unilateral upper extremity (Hirayama disease)-half-century progress and establishment since its discovery]. Brain Nerve 2008;60(01):17-29 Japanese

2 Hirayama K, Tomonaga M, Kitano K, Yamada T, Kojima S, Arai K. Focal cervical poliopathy causing juvenile muscular atrophy of distal upper extremity: a pathological study. J Neurol Neurosurg Psychiatry 1987;50(03):285-290

3 Hassan KM, Sahni H, Jha A. Clinical and radiological profile of Hirayama disease: a flexion myelopathy due to tight cervical dural canal amenable to collar therapy. Ann Indian Acad Neurol 2012; 15(02):106-112

4 Kohno M, Takahashi H, Yagishita A, Tanabe H. "Disproportion theory" of the cervical spine and spinal cord in patients with juvenile cervical flexion myelopathy. A study comparing cervical magnetic resonance images with those of normal controls. Surg Neurol 1998;50(05):421-430

5 Mitsui K, Iida H, Tachibana S. Yada [Surgical treatment for flexion myelopathy with overstretch syndrome]. Nippon Seikeigeka Gakkai Zasshi 1990;64:325 Japanese

6 Song J, Wang HL, Zheng CJ, Jiang JY. Risk factors for surgical results of Hirayama disease: a retrospective analysis of a large cohort. World Neurosurg 2017;105:69-77

7 Watanabe K, Hasegawa K, Hirano T, Endo N, Yamazaki A, Homma T. Anterior spinal decompression and fusion for cervical flexion myelopathy in young patients. J Neurosurg Spine 2005;3(02): 86-91

8 Zheng C, Nie C, Lei W, et al. CAN anterior cervical fusion procedures prevent the progression of the natural course of Hirayama disease? An ambispective cohort analysis. Clin Neurophysiol 2018;129(11):2341-2349

9 Odom GL, Finney W, Woodhall B. Cervical disk lesions. J Am Med Assoc 166:23-28 with overstretch syndrome]. Nippon Seikeigeka Gakkai Zasshi 1958;64:325 Japanese

10 Broekema AEH, Molenberg R, Kuijlen JMA, Groen RJM, Reneman MF, Soer R. The Odom criteria: validated at last: a clinimetric evaluation in cervical spine surgery. J Bone Joint Surg Am 2019; 101(14):1301-1308

11 Hamilton DF, Giesinger JM, Giesinger K. It is merely subjective opinion that patient-reported outcome measures are not objective tools. Bone Joint Res 2017;6(12):665-666

12 Simard J, Chalifoux M, Fortin V, Archambault MJ, St-Cerny-Gosselin A, Desrosiers J. Could questions on activities of daily living estimate grip strength of older adults living independently in the community? J Aging Res 2012;2012:427109

$13 \mathrm{Xu} \mathrm{H}$, Shao M, Zhang F, et al. Snake-eyes appearance on MRI occurs during the late stage of Hirayama disease and indicates poor prognosis. BioMed Res Int 2019;2019:9830243

14 Lapresle J. [Clinical and neuropathological aspects of circulatory disorders of the spinal cord]. Bull Schweiz Akad Med Wiss 1969; 24(05):512-528 French

15 Imai T, Shizukawa $\mathrm{H}$, Nakanishi $\mathrm{K}$, et al. Hyperexcitability of cervical motor neurons during neck flexion in patients with Hirayama disease. Electromyogr Clin Neurophysiol 2000;40 (01):11-15

16 Ciceri EF, Chiapparini L, Erbetta A, et al. Angiographically proven cervical venous engorgement: a possible concurrent cause in the pathophysiology of Hirayama's myelopathy. Neurol Sci 2010;31 (06):845-848

17 Kikuchi S, Tashiro K, Kitagawa M, Iwasaki Y, Abe H. [A mechanism of juvenile muscular atrophy localized in the hand and forearm (Hirayama's disease)-flexion myelopathy with tight dural canal in flexion]. Rinsho Shinkeigaku 1987;27(04):412-419 Japanese

18 Mochizuki M, Goto S, Kita T, Kobayashi K, Sodeyama T, Murata J. [Evaluation of the dynamicity of spinal cord and dura mater until neck full flexion in flexion myelopathy and the histopathologhy of its dura mater]. Seikei Geka 1996;47:162-166 Japanese

19 Yoshiyama Y, Tokumaru Y, Arai K. Flexion-induced cervical myelopathy associated with fewer elastic fibers and thickening in the posterior dura mater. J Neurol 2010;257(01):149-151

20 Khadilkar S, Patel B, Bhutada A, Chaudhari C. Do longer necks predispose to Hirayama disease? A comparison with mimics and controls. J Neurol Sci 2015;359(1-2):213-216

21 Brandicourt P, Sol JC, Aldéa S, Bonneville F, Cintas P, Brauge D. Cervical laminectomy and micro resection of the posterior venous plexus in Hirayama disease. Neurochirurgie 2018;64(04):303-309

22 Patel TR, Chiocca EA, Freimer ML, Christoforidis GA. Lack of epidural pressure change with neck flexion in a patient with Hirayama disease: case report. Neurosurgery 2009;64(06): E1196-E1197, discussion E1197

23 Goel A, Dhar A, Shah A. Multilevel spinal stabilization as a treatment for Hirayama disease: report of an experience with five cases. World Neurosurg 2017;99:186-191

24 Song J, Cui ZY, Chen ZH, Jiang JY. Analysis of the effect of surgical treatment for the patients with Hirayama disease from the perspective of cervical spine sagittal alignment. World Neurosurg 2020;133:e342-e347

$25 \mathrm{Xu} \mathrm{X}$, Han H, Gao H, et al. The increased range of cervical flexed motion detected by radiographs in Hirayama disease. Eur J Radiol 2011;78(01):82-86

26 Lyu $\mathrm{F}$, Zheng C, Wang $\mathrm{H}$, et al. Establishment of a clinician-led guideline on the diagnosis and treatment of Hirayama disease using a modified Delphi technique. Clin Neurophysiol 2020;131 (06):1311-1319

27 Tokumaru Y, Hirayama K. [Cervical collar therapy for juvenile muscular atrophy of distal upper extremity (Hirayama disease): results from 38 cases]. Rinsho Shinkeigaku 2001;41(4-5):173-178 Japanese.

28 Aita I, Hayashi K, Wadano Y, Yabuki T. Posterior movement and enlargement of the spinal cord after cervical laminoplasty. J Bone Joint Surg Br 1998;80(01):33-37 Erratum in: J Bone Joint Surg Br 82:1092

29 Matsuyama Y, Kawakami N, Mimatsu K. Spinal cord expansion after decompression in cervical myelopathy. Investigation by computed tomography myelography and ultrasonography. Spine 1995;20(15):1657-1663

30 Baba $\mathrm{Y}$, Nakajima M, Utsunomiya $\mathrm{H}$, et al. Magnetic resonance imaging of thoracic epidural venous dilation in Hirayama disease. Neurology 2004162(08):1426-1428

31 Chen CJ, Chen CM, Wu CL, Ro LS, Chen ST, Lee TH. Hirayama disease: MR diagnosis. AJNR Am J Neuroradiol 1998;19(02): 365-368

32 Lai V, Wong YC, Poon WL, Yuen MK, Fu YP, Wong OW. Forward shifting of posterior dural sac during flexion cervical magnetic resonance imaging in Hirayama disease: an initial study on normal subjects compared to patients with Hirayama disease. Eur J Radiol 2011;80(03):724-728

33 Mukai E, Sobue I, Muto T, Takahashi A, Goto S. [Abnormal radiological findings in juvenile-type distal and segmental muscular atrophy of the upper extremities]. Rinsho Shinkeigaku 1985;25(05):620-626 Japanese

34 Lyu RK, Huang YC, Wu YR, et al. Electrophysiological features of Hirayama disease. Muscle Nerve 2011;44(02):185-190 
35 Kalita J, Kumar S, Misra UK, Neyaz Z. Split hand index and ulnar to median ratio in Hirayama disease and amyotrophic lateral sclerosis. Amyotroph Lateral Scler Frontotemporal Degener 2017;18(78):598-603

36 Ito H, Takai K, Taniguchi M. Cervical duraplasty with tenting sutures via laminoplasty for cervical flexion myelopathy in patients with Hirayama disease: successful decompression of a "tight dural canal in flexion" without spinal fusion. J Neurosurg Spine 2014;21(05):743-752

37 Arrese I, Rivas JJ, Esteban J, Ramos A, Lobato RD. A case of Hirayama disease treated with laminectomy and duraplasty without spinal fusion. Neurocirugia (Astur) 2009;20(06): 555-558, discussion 558

38 Fujimoto Y, Oka S, Tanaka N, Nishikawa K, Kawagoe H, Baba I. Pathophysiology and treatment for cervical flexion myelopathy. Eur Spine J 2002;11(03):276-285

39 Lin MS, Kung WM, Chiu WT, Lyu RK, Chen CJ, Chen TY. Hirayama disease. J Neurosurg Spine 2010;12(06):629-634

40 Vitale V, Caranci F, Pisciotta C, et al. Hirayama's disease: an Italian single center experience and review of the literature. Quant Imaging Med Surg 2016;6(04):364-373
41 Ryken TC, Heary RF, Matz PG, et al; Joint Section on Disorders of the Spine and Peripheral Nerves of the American Association of Neurological Surgeons and Congress of Neurological Surgeons. Cervical laminectomy for the treatment of cervical degenerative myelopathy. J Neurosurg Spine 2009;11(02): $142-149$

42 Jain A, Rustagi T, Prasad G, Deore T, Bhojraj SY. Does segmental kyphosis affect surgical outcome after a posterior decompressive laminectomy in multisegmental cervical spondylotic myelopathy? Asian Spine J 2017;11(01):24-30

43 Hukuda S, Ogata M, Mochizuki T, Shichikawa K. Laminectomy versus laminoplasty for cervical myelopathy: brief report. J Bone Joint Surg Br 1988;70(02):325-326

44 Lao L, Zhong G, Li X, Qian L, Liu Z. Laminoplasty versus laminectomy for multi-level cervical spondylotic myelopathy: a systematic review of the literature. J Orthop Surg Res 2013;8:45

45 Nurboja B, Kachramanoglou C, Choi D. Cervical laminectomy vs laminoplasty: is there a difference in outcome and postoperative pain? Neurosurgery 2012;70(04):965-970, discussion 970 